\title{
Demand Forecasting and Inventory Prediction for Apparel Product using the ARIMA and Fuzzy EPQ Model
}

\author{
Tran Thi Bich Chau Vo", ${ }^{1, *}$ Phan Hung Le ${ }^{2}$, Nhut Tien Nguyen ${ }^{3}$, Thi Le Thuy Nguyen ${ }^{1}$ and Ngoc Hien \\ $\mathrm{Do}^{4}$ \\ ${ }^{1}$ Department of Industrial Management, Can Tho University, Can Tho, Vietnam \\ ${ }^{2}$ Department of Mechatronics Engineering, Ho Chi Minh City University of Technology and Education, Ho Chi Minh City, Vietnam \\ ${ }^{3}$ Department of Electrical Engineering, Can Tho University, Can Tho, Vietnam \\ ${ }^{4}$ Department of Industrial and Systems Engineering, Hochiminh City University of Technology, Vietnam
}

Received 27 November 2020; Accepted 10 April 2021

\begin{abstract}
Demand forecasting is essential for almost companies, especially in the garment industry. Accurate forecasting will provide data input for efficient production, inventory, and distribution planning, thereby helping businesses reduce operating costs and improve supply efficiency. This paper will forecast demand for long-sleeved shirts at Tay Do Garment Company with ARIMA (Autoregressive Integrated Moving Average) model. Firstly, monthly data from January 2016 to December 2020 build models based on the Arima model. The results indicated better efficiency after comparing ARIMA accuracy with Holt's regression model. Besides, the ARIMA model is predicted demand for the period from January 2021 to December 2021. Moreover, the forecast data will be used to survey the "Fuzzy economic production quantity" (Fuzzy EPQ) inventory model. Besides, using Arena software is to simulate the production speed of the line. Finally, the optimal batch size per production lot and the number of production times per year to minimize costs are suggested.
\end{abstract}

Keywords: Forecasting demand, inventory prediction, long sleeve shirt products, ARIMA, Fuzzy economic production quantity.

\section{Introduction}

In the current market economy, the competition between businesses is increasingly fierce. Companies need to have appropriate strategies, such as potential customers, pricing strategies, product quality improvement, and new product development, which means that companies want to survive and grow. Besides, capturing market demand also plays an essential part in helping businesses be more proactive in production and rationally balance resources, minimize backlog, storage costs, and bring many other practical benefits. This issue requires firms to pay attention to forecast work because forecasting is the most effective method to know market demand. Indeed, forecasting is a necessary and indispensable activity for any business. Accurate forecasting allows us to implement production management plans such as order planning, production strategy selection, material demand planning, and inventory management. From there, improving operational efficiency and competitiveness, reducing costs, and increasing profits are made better. The prediction process was initially based on a unique technique [1]. Forecasting is considered one of the most critical factors in decision making [2]. There have been many studies on the application of forecasting models for each business sector. A researcher applied forecasting methods for electricity and gas use [3]. The forecast model should update the forecast time and weather impact on the increase in electrical goods sales when the weather is hotter. Peak forecast for long-term planning and short-term consumption of electricity and gas products; Therefore, a regression model and econometric

*E-mail address: vttbchau@ctu.edu.vn

ISSN: 1791-2377 @ 2021 School of Science, IHU. All rights reserved.

doi:10.25103/jestr.142.11 model are proposed to forecast sales for local and primary customers. Besides, another researcher has applied the forecasting methods in revenue forecasting in hotel management. Study has shown that the Winters model is suitable for a series of seasonal and trendy data [4]. An overview of predictive techniques for industrial applications was also made by Vera et al. This study compared the predicted value's predictive accuracy through arithmetic mean and minimum variance, taking into account correlation errors in single forecasts. The available models used for the combination are SARIMA and ANN; the chosen accuracy measurement methods are MAPE, MSE, and MAE. The results show that the minimum variance is very dominant in the simple combination method [5]. Andrawis et al. used combined forecasting techniques to improve accuracy by integrating different periods to utilize multiple information sources. The article has demonstrated the advantages of combined prediction over available forecasts [6]. Specifically, Newbold also has research on the effectiveness of combining predictive models to improve predicting earnings per share [7]. Analysts' predictions are more accurate than predictions of models that use only historical data. However, research also shows that earnings per share forecast can be improved by incorporating analysts' and other models' predictions. Specifically, predictive errors are minimal when the analyst's projection is combined with the ARIMA model. In Vietnam, the researches and application of these prediction methods in our country are still minimal. Specially, B. Q. Trung et al. used the ARIMA model in forecasting the VN_Index. VN_Index data was collected from a website providing data on the Vietnam stock market from January 2, 2009, to March 30, 2010 [8]. Therefore, this article focuses 
on this forecasting method and is the first step for Vietnamese enterprises.

In recent years, Vietnam's advantages of abundant labor resources, low operating costs, and a large consumer market have created a driving force for the garment industry to thrive on being the key field in the economy. Simultaneously, there are still many difficulties hindering the industry's development, such as low product added value and intense competitiveness, the cause of which is identified as weak supply capacity. Specifically, inadequacies in demand forecasting and other logistics activities are the top issues that companies need to address to improve their efficiency. According to the Ministry of Industry and Trade, 2020 is an incredibly difficult year for the textile and garment industry of Vietnam when it has many complicated and difficult forecast fluctuations. Under the impact of the COVID-19 epidemic, textiles and garments are initiatives with tremendous direct losses, along with tourism, aviation, and footwear. Demand slowed down due to the COVID-19 epidemic. When consumers worldwide only paid attention to essential equipment and disease prevention, Vietnamese textile and garment enterprises faced many difficulties due to short orders. Hence, the Vietnamese textile and garment enterprise has implemented the rapid transformation of traditional goods' structure to fast adaptive items such as workwear, knitwear, and formal shirts to maintain production and business activities. At the same time, Textile enterprises must-have to change the mode of production and business, suit the unique situation, exploit and expand the domestic market, and actively link with customers to form a production chain.

In the current fierce competition period, businesses need to make changes such as technology improvement, product quality improvement, and brand promotion. Besides, useful forecasts help the company be more proactive in production and quickly cope with fluctuations in the market. Indeed, the forecast results will be the basis for businesses to implement production management plans such as selecting production strategies, planning material demand, managing inventory, and improving operational efficiency and competitiveness. However, forecasts have not been given due attention by businesses operating in the apparel sector, mainly based on experience. These methods will be directly applied to specific data to evaluate and prove its effectiveness.

\section{Literature Review}

\subsection{Demand forecasting}

Forecasting is a combination of science and art, used to predict events before they occur in the future. Demand forecasting has a strong influence on manufacturing and service firms' decision-making because it predicts relatively accurately uncertain events and reduces risk mitigation. A sound forecasting system requires choosing the right forecasting techniques for each type of product and tracking error ranges for prediction, evaluating, and editing interpredictive models procedures to minimize negative impacts on governance [9].

There are several studies about forecast demand in the apparel industry. It cannot be denied that demand forecasting is an important issue to promote effective operational management plans. In the apparel industry, uncertain needs, lack of historical data, and seasonal trends often coexist [10]. Demand forecasting in the apparel industry is incredibly complicated when companies have many products with short lifecycles, deeply influenced by promotional events, weather conditions, and socio-economic factors [11]. Input data for forecasting in garment companies can be collected from two sources, including demand statistics from the past periods or business managers' opinions. The results show that the majority of products are forecasted short term by available data provides good results. The expert evaluation method performed better for a small group of products than past demand information [12]. A study forecasted women's apparel sales based on two approaches, such as time series analysis and soft computation. This study used a 4-year data set (1997-2000) to predict the next two months, and the author commented that time series analysis is an advantageous method in forecasting apparel sales [13].

ARIMA model has been considered a useful method of forecasting trends and seasonal fluctuations. One study applied the ARIMA model to help farmers determine daily harvested volumes of fruits and vegetables. The results show that the model can indicate demand with the mean absolute percent error (MAPE) of 43.14\% [14]. According to a sales forecast study for the distributor in the plastic industry, the ARIMA model has been compared efficiency with Holt's method by using MAPE (Mean Absolute Percentage Error). The results indicated that ARIMA provided the most effective forecast because of the best MAPE [15]. The suitable models are selected according to criteria such as an Akaike criterion, Schwarz Bayesian criterion, maximum likelihood, and standard error. The results showed that the ARIMA model $(1,0,1)$ is the most suitable to forecast the Company's future demand. This study also demonstrates how historical data can predict the future direction and its effect on supply chains [16]. Many studies have implemented the Arima model in many fields. Ang expects US inflation using various individual methods such as the time series model, ARIMA model, trend line model, and survey results. The study concludes that the surveys outperform other predictive methods and that structural engineering performs relatively poorly [17]. However, combining forecasts will give better results and have the highest accuracy if the data is based on the survey information. In another study on inflation forecasting in the US, Poncela argued that a combination of individual projections is often a useful tool for improving accuracy [18]. The most commonly used technique for combination prediction is a simple average. He reviewed and analyzed the factors affecting the US inflation forecast combination. The results show that only one element is not enough to overcome the mean method's limitation, so having the second factor is necessary. The first factor is usually the weighted average of the variables, and it can be interpreted as a consensus forecast.

In contrast, the second factor usually provides the difference between the variables and from observations. As forecasts, it can increase the accuracy and reduce deviation from the consensus forecast. Meanwhile, a group combines component methods such as ARIMA, SP spectrum model, VAR to forecast US inflation [19]. After research, he argues that forecasting inflation from multiple models produces a more accurate forecast value than any particular model and increases the policy decisions' reliability. This result is consistent with the US central bank's previous combined model approach. Senlen Baser uses ARIMA, AR, nonlinear modeling, VAR, and combined techniques for prediction. The study found that the model incorporating much better financial information, and integrating the forecast leads to a reduction in predictive error compared with most models. However, some individual models perform well in certain 
forecast intervals. Because the accuracy can be significantly increased, the authors' combined technique continues to be used to forecast inflation in some countries. Lack chose the Vector self-regression model (VAR) and a dissociation model to forecast Swiss inflation. However, to test and improve the procedures' quality, the methods' results are compared and combined with these two methods [20]. Post-study shows that combining prediction enhances the quality of forecasts. Moser combines the VAR model, ARIMA model, cause, and effect model to create an Australian inflation forecast. The results show that the causal model has the highest accuracy, and the prediction accuracy can be further improved by combining factors and VAR models [21]. Meanwhile, Fang demonstrates why a single forecast can be connected to create a comprehensive and superior forecast compared to individual predictions. The author uses ARIMA, VAR, and a simple average combination to forecast quarterly consumption costs in the UK [22].

\subsection{Production Inventory Planning}

There have been many studies on inventory management for businesses, especially in the garment industry. An investigation has been conducted on inventory management at a textile chain store in Malaysia. The primary purpose of this study is to test the relationship between inventory management and corporate performance. This research showed that the Company encounters several inventory management problems, including unorganized operations, unspecified arrangements, quantity, and inventory timing that are not checked and recorded precisely. Besides, the study demonstrated that it had existed an inverse relationship between the net return on assets (ROA) and the inventory time (when inventory time increases by $1 \%$, ROA decreases $0.0761 \%$ ) [23].

On the other hand, a paper has presented the results of a case study conducted in industrial companies in some developing countries to examine existing inventory control issues. This article stated that manufacturers try to keep a large inventory level to avoid shortage due to unstable demand. They consider inventory cost an obvious expense, but this reduces business efficiency and competing capability [24]. An investigating factor affecting inventory management of small and medium enterprises has been performed. The results showed that SMEs' most common inventory management problems are overproduction, over-inventory, delay in raw material supply, and discrepancies. Warehouse management records [25]. Inventory management, especially in a mass-production system, plays a critical role in every company.

In mass production systems, economic production quantity (EPQ) models are developed throughout many approaches to minimize inventory costs. A model for raw material cost and finished products was used to optimize the ordering policy for the procurement of raw materials and batch size to minimize total cost to meet customer demand promptly. Simultaneously, the relationship depends on the production batch size, and the number of raw material purchases for the same factors is also considered [26]. Furthermore, a case study of inventory in apparel and electronics manufacturing was carried out to integrate the selling price and quality ratio into a mathematical model to optimize the economic production quantity model [27]. A study showed production speed on production batch size in the EPQ model was introduced. In this article, a mathematical model was to determine the optimal inventory under variable production rate conditions [28]. The research was also presented that determined the optimal batch size with a controlled production rate [29].

The fuzzy theory has long been widely applied in various fields, especially in inventory planning. A study solved the problem of economic production (EPQ) by blurring demand and production per day. The results show that the fuzzy model's total cost is slightly higher than the traditional one, but it is more appropriate while demand and production volume fluctuate [30]. Also, a study presented the programming geometry approach of the fuzzy EPQ model. In this paper, an EPQ model is developed considering the flexibility and reliability of the production process and the unit production cost depending on demand. Besides, the model also adds constraints to restrict storage space. The model was built in a fuzzy environment by blurring the objective function's coefficients and regulation. The results indicated that this model could help managers make highly effective and reliable decisions [31]. In another study by a realistic inventory model with fuzzy costs was developed. An inventory system that minimizes inventory costs is proposed to adopt the expressions for the retailer's total annual inventory cost in both a clear and fuzzy sense [32].

\section{Research Methodology}

This study is carried out in the following five steps shown in Figure 1.

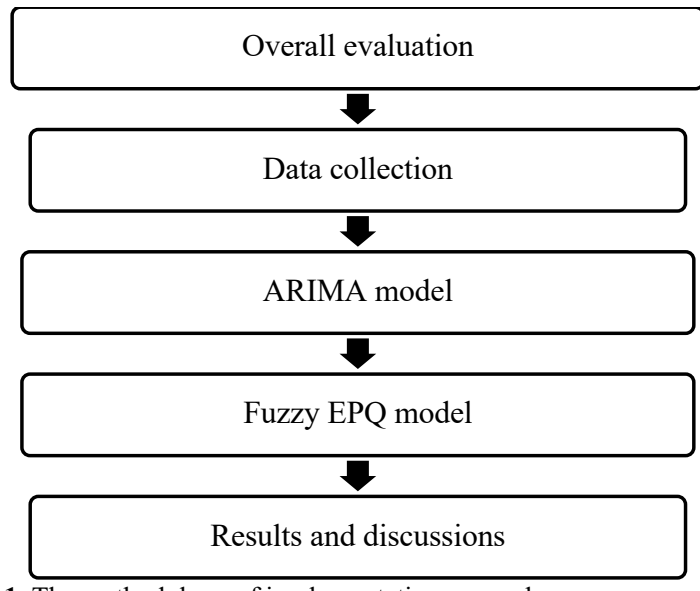

Fig. 1. The methodology of implementation research

After a field survey at the company, it was found that demand forecasting and inventory planning were done without scientific calculation, mostly based on management's experience. Consequences of that have been mentioned in Section 1. Therefore, this study proposes to use the ARIMA forecasting model and Fuzzy EPQ inventory model to improve the current situation. Firstly, the research will collect the necessary data at the company using field surveys and available data to achieve the stated goals. The production process's actual investigation at the production line and collects data such as a workstation, workstation time (using a stopwatch), production line diagram, work-time production, production, and inventory costs. Next, monthly sales figures from 2016 to 2020 are collected from the company's sales department. Currently, the company is trading many types of shirts, but the topic will focus on researching the main product line with the product code TMBL1. Secondly, the ARIMA model's development requires the following five steps by Box-Jenkins methodology: static data checking, model identification, parameter estimation, diagnostic checking, and 
forecasting in this study [33]. Thirdly, a simulation model was built from the production line survey data using Arena software to determine the production rate. Besides, the fuzzy number method is applied to assess inventory costs and production setup costs. From the analyzed data, the study will propose the optimal production batch size. Implementation details are presented in section 4. Finally, the study results will be aggregated and will also mention limitations and further research directions.

\section{Case Study}

\subsection{Overall evaluation}

The topic is also towards the interest and widespread application of businesses. For the above reason, Tay Do Garment Joint Stock Company is continuously improving its product supply chain. Annually, the company provides many shirts, trousers, uniforms with diverse and quality designs to meet export orders and serve domestic needs. However, the company realized that there are still many shortcomings in its supply chain, reflected in high operating costs, but there is often a shortage of goods. The above situation was analyzed and determined that the demand forecast was insufficient, causing a large error between the prediction and actual demand. The input data for planning is inaccurate. Besides, the company makes the stock system also suffer from several problems such as optimal unspecified batch size and several production times per year, increasing the company's cost and adversely affecting the function to meet customers' needs. Therefore, this study is to conduct enhancement supply longsleeved shirts of Tay Do Garment Joint Stock Company. This study will build an ARIMA model for the long-sleeved shirt produced at the company TMBL1. The forecast period will be 12 months from $01 / 2021$ to $12 / 2021$. The collection of past data includes 60 periods, sales per month of the product line from 2016 to 2020 . E-view software will be used to analyze data and forecast. The forecast data will be used for future inventory calculations.

\subsection{Data overview}

The paper used the data visualization method to evaluate data characteristics. Observing Figure 2, the graph representing the data gives us the assumption that: TMBL1 products have a fluctuating sales volume between months and an increasing trend over the years. Indeed, a review of the statistics depicted in Figure 2 shows that the data series has an uneven distribution (standard deviation of 152). Besides, when looking at the separate graph for each year, we also see that the data is not the same over the years to reject the data (Figure 3). The actual monthly demand from 2016 to 2020 (60 observations) are presented in Figure 4.

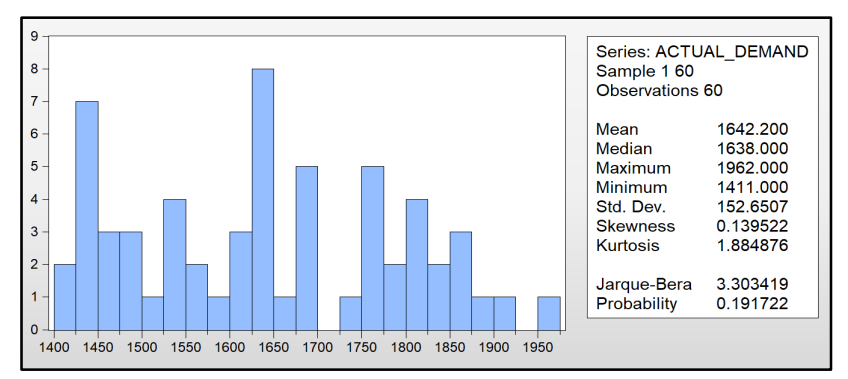

Fig. 2. Descriptive statistics of the data series

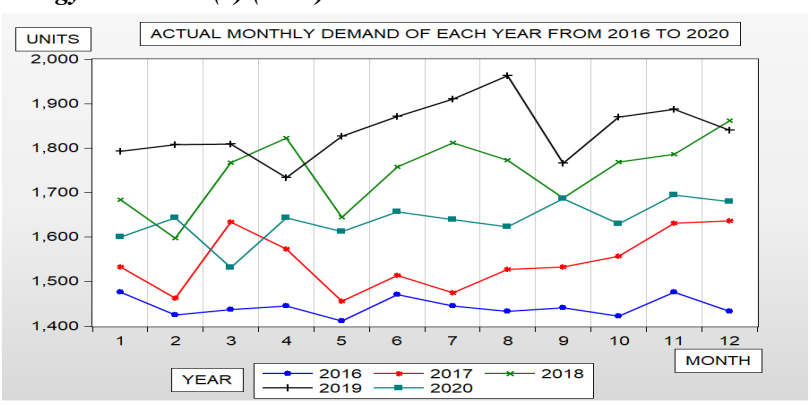

Fig. 3. Actual monthly demand from 2016 to 2020

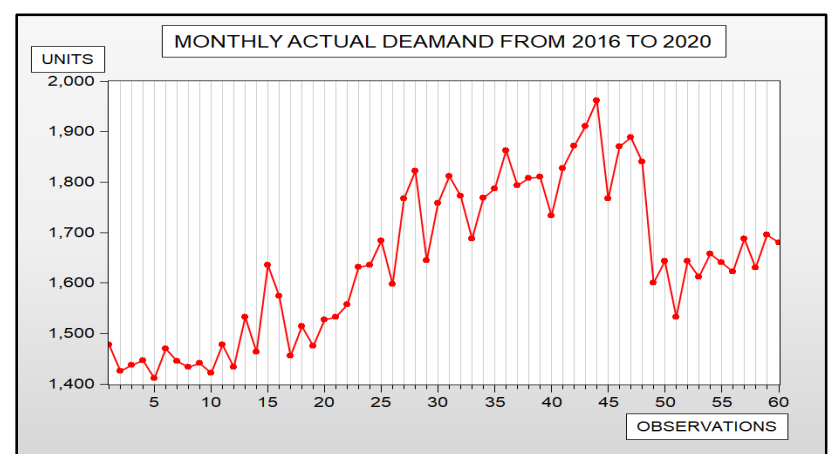

Fig. 4. Actual demand from 2016 to 2020 for TMBL1

\subsection{Demand forecasting models}

\subsubsection{ARIMA model}

ARIMA models are generally denoted ARIMA(p,d,q) where parameters $p, d$, and $q$ are non-negative integers, $p$ is the autoregressive model's order, $\mathrm{d}$ is the degree of differencing, and $\mathrm{q}$ is the order of the moving-average model. Firstly, we need to consider whether the data series is stationary or not before building the ARIMA model, and the ADF (Augmented Dickey-Fuller) test is conducted to determine. In the ADF test, we will consider the absolute value of ADF with the total value of t-statistic; if the value of absolute ADF is greater than the absolute value of $t$ - statistic, the data series under consideration is not stationary. The results presented Table 1 show that the total value of ADF is greater than the absolute value of t-statistic at the statistical significance of $1 \%, 5 \%$, and $10 \%$, so concluding the series data is not stationary. Therefore, we need to use different methods to get a new series.

Table 1. ADF test results of data series

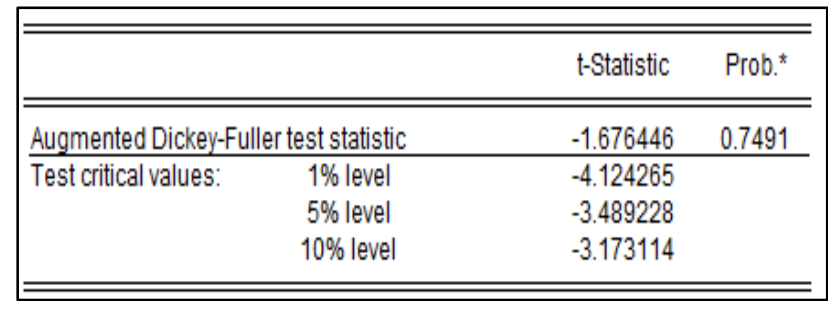

After taking the difference and examining the ADF test on the new data series, it was found that the original series was stationary because the absolute values of the ADF were all less than the fundamental values of t-statistic at the significance levels of $1 \%, 5 \%$ and $10 \%$ (Table 2 ). Thus, the ARIMA model determines the difference degree is $1(\mathrm{~d}=1)$.

To determine the $\mathrm{p}$ and $\mathrm{q}$ of the model, we need to base on Table 3, the other partial autocorrelation coefficients are not statistically significant at $\mathrm{k}=1$ and 2 and then fade to zero. 
Tran Thi Bich Chau Vo, Phan Hung Le, Nhut Tien Nguyen, Thi Le Thuy Nguyen and Ngoc Hien Do/

Journal of Engineering Science and Technology Review 14 (2) (2021) 80 - 89

Besides, we have a non-zero correlation coefficient of ACF at $\mathrm{k}=1$, and 16 then descend to 0 . Therefore, we can choose $\mathrm{p}$ $=1$ and $\mathrm{q}=1,16$.

Table 2. ADF test results of difference data series

\begin{tabular}{lrrr}
\hline \hline & t-Statistic & Prob. \\
\hline \hline Augmented Dickey-Fuller test statistic & -11.26989 & 0.0000 \\
\hline Test critical values: & $1 \%$ level & -4.124265 & \\
& $5 \%$ level & -3.489228 & \\
& $10 \%$ level & -3.173114 & \\
\hline \hline
\end{tabular}

Table 3. ACF và $\mathrm{PACF}$ correlograms

\begin{tabular}{|c|c|c|c|c|c|c|c|}
\hline Autocorrelation & Partial Co & orrelation & & $A C$ & PAC & Q-Stat & Prob \\
\hline$\square$ & $\square$ & & & -0.386 & -0.386 & 9.2598 & 0.002 \\
\hline 11 & 14 & 1 & 2 & 0.027 & -0.144 & 9.3062 & 0.010 \\
\hline 10 & 10 & 1 & & -0.032 & -0.091 & 9.3731 & 0.025 \\
\hline 101 & 1 & 1 & 4 & 0.070 & 0.031 & 9.6956 & 0.046 \\
\hline 101 & 10 & 21 & 5 & 0.036 & 0.092 & 9.7826 & 0.082 \\
\hline 10 & 10 & 1 & & -0.136 & -0.093 & 11.039 & 0.087 \\
\hline 181 & 1 & 1 & 7 & 0.067 & -0.023 & 11.351 & 0.124 \\
\hline 11 & 10 & 1 & 8 & -0.047 & -0.055 & 11.507 & 0.175 \\
\hline 171 & 1 & 1 & 9 & 0.063 & 0.019 & 11.790 & 0.225 \\
\hline 101 & 10 & 1 & 10 & -0.096 & -0.062 & 12.464 & 0.255 \\
\hline 11 & 10 & 1 & 11 & -0.019 & -0.086 & 12.490 & 0.328 \\
\hline اص & 10 & יו" & 12 & 0.186 & 0.157 & 15.133 & 0.234 \\
\hline 101 & 17 & 21 & 13 & -0.089 & 0.056 & 15.747 & 0.263 \\
\hline 101 & 10 & 1 & 14 & -0.066 & -0.082 & 16.090 & 0.308 \\
\hline 101 & 1드 & 1 & 15 & -0.086 & -0.165 & 16.692 & 0.338 \\
\hline $1 \boxminus$ & 10 & اص & 16 & 0.282 & 0.182 & 23.371 & 0.104 \\
\hline 1 . 1 & $1 p$ & 1 & 17 & -0.107 & 0.081 & 24.348 & 0.110 \\
\hline 1 1 1 & 1 다 & 1 & 18 & -0.113 & -0.099 & 25.472 & 0.112 \\
\hline 101 & 1 & 1 & 19 & 0.068 & -0.011 & 25.884 & 0.133 \\
\hline 11 & 1 & 1 & 20 & 0.007 & 0.004 & 25.888 & 0.170 \\
\hline 111 & 1 & 1 & 21 & 0.048 & 0.016 & 26.111 & 0.202 \\
\hline 1 & 10 & 1 & 22 & -0.146 & -0.074 & 28.187 & 0.170 \\
\hline 101 & 1 & 1 & 23 & 0.079 & -0.002 & 28.817 & 0.186 \\
\hline 101 & 1 미 & 1 & 24 & -0.057 & -0.092 & 29.156 & 0.214 \\
\hline
\end{tabular}

ARIMA models have been identified and tested include: ARIMA $(0,1,1)$, ARIMA $(0,1,16)$, ARIMA $(1,1,1)$, ARIMA $(1,1,16)$, and ARIMA $(1,1,0)$. The above models are compared for suitability based on the post-regression test parameters, including: adjusted $\mathrm{R}^{2}$, Akaike's Information Criterion (AIC) to choose the most suitable model. The most suitable model has the largest adjusted $\mathrm{R}^{2}$ and the smallest AIC . The test results are shown in Table 4. The results show that ARIMA $(1,1,16)$ is the most suitable. Then, we use the least-squares method to estimate the coefficient. The estimated results are shown in Table 5.

Table 4. Test results of proposed ARIMA models

\begin{tabular}{c|c|c}
\hline ARIMA(p,d,q) & Adjusted R2 & AIC \\
\hline$(0,1,1)$ & 0.16 & 11.47 \\
$(0,1,16)$ & 0.44 & 11.05 \\
$(1,1,1)$ & 0.14 & 11.51 \\
$(1,1,16)$ & 0.50 & 10.10 \\
$(1,1,0)$ & 0.13 & 11.50 \\
\hline
\end{tabular}

The model is checked for the data series's suitability by analyzing whether the residual is white noise or not. Based on the autocorrelation function diagram (ACF) in Table 6, we can see that the values are in the limit to identify the remainder as white noise. Therefore, we can use the ARIMA model $(1,1,16)$ to forecast demand, and the results are shown in Figure 5. Forecasting monthly demand in 2021 is presented in Table 7.
Table 5. Results of the estimation coefficient of the ARIMA model $(1,1,16)$

\begin{tabular}{|lrlll|}
\hline \hline \multicolumn{1}{c}{ Variable } & Coefficient & Std. Error & t-Statistic & Prob. \\
\hline \hline C & 2.071558 & 9.853249 & 0.210241 & 0.8343 \\
ARA(16) & -0.331002 & 0.127614 & -2.593784 & 0.0121 \\
MA(16) & 0.860473 & 0.030003 & 28.67998 & 0.0000 \\
\hline \hline R-squared & 0.515393 & Mean dependent var & 4.396552 \\
Adjusted R-squared & 0.497771 & S.D. dependent var & 80.74672 \\
S.E. of regression & 57.22370 & Akaike info criterion & 10.98215 \\
Sum squared resid & 180100.4 & Schwar criterion & 11.08873 \\
Log likelihood & -315.4824 & Hannan-Quinn criter. & 11.02366 \\
F-statistic & 29.24698 & Durbin-Watson stat & 1.976727 \\
Prob(F-statistic) & 0.0000000 & & & \\
\hline \hline
\end{tabular}

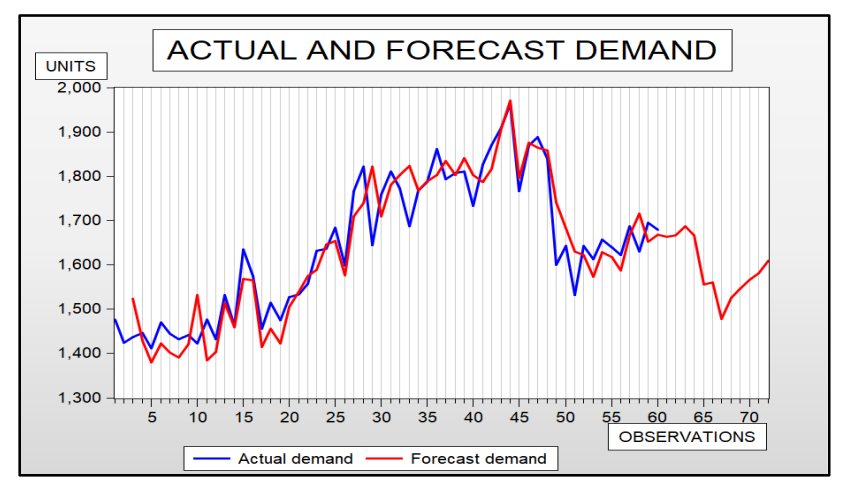

Fig. 5. Forecast and actual demand for TMBL1

Table 6. Correlogram of residual

\begin{tabular}{|c|c|c|c|c|c|}
\hline \multicolumn{6}{|c|}{$\begin{array}{l}\text { Included observations: } 58 \\
\text { Q-statistic probabilities adjusted for } 2 \text { ARMA term(s) }\end{array}$} \\
\hline Autocorrelation & Partial Correlation & $A C$ & PAC & Q-Stat & Prob \\
\hline 111 & 111 & $1-0.013$ & -0.013 & 0.0111 & \\
\hline 11 & 121 & $2-0.034$ & -0.034 & 0.0832 & \\
\hline 11 & 10 & $3-0.041$ & -0.042 & 0.1889 & 0.564 \\
\hline 1 1 & 1 户 & $\begin{array}{ll}4 & 0.110\end{array}$ & $0.10 \sqrt{3}$ & 0.9754 & 0. 314 \\
\hline 101 & & $5-0.053$ & $-0.05 / 4$ & 1.1583 & 0.763 \\
\hline & $1] 1$ & $\begin{array}{ll}6 & 0.006\end{array}$ & 0.011 & 1.1607 & 0.385 \\
\hline 1 1 1 & 1 1 & $\begin{array}{ll}7 & 0.082\end{array}$ & 0.089 & 1.6139 & 0.900 \\
\hline & $1[1$ & $\begin{array}{ll}8 & 0.000\end{array}$ & -0.015 & 1.6140 & 0.552 \\
\hline 11 & 1 & $\begin{array}{l}9 \\
9\end{array} 0.008$ & 0.027 & 1.6189 & 0.778 \\
\hline 111 & $1 \mid 1$ & $10-0.015$ & -0.013 & 1.6363 & 0.990 \\
\hline יط 1 & ו י & $11 \quad 0.178$ & 0.164 & 3.9740 & 0.813 \\
\hline $1 \sqrt{1}$ & 151 & $12 \quad 0.050$ & 0.065 & 4.1600 & 0.940 \\
\hline 101 & 14 & $13-0.049$ & -0.043 & 4.3488 & 0.959 \\
\hline 151 & 151 & $14-0.086$ & $-0.07 / 2$ & 4.9327 & 0.960 \\
\hline 1 & 1 & $15-0.055$ & -0.097 & 5.1766 & 0.971 \\
\hline $1 \mathrm{p}$ & 101 & $\begin{array}{ll}16 & 0.089\end{array}$ & 0.089 & 5.8356 & 0.970 \\
\hline $1[1$ & $1 \longdiv { 1 }$ & $17 \quad 0.007$ & 0.014 & 5.8402 & 0.882 \\
\hline 151 & 151 & $18-0.071$ & -0.098 & 6.2847 & 0.985 \\
\hline ים 1 & יש 1 & $19 \quad 0.166$ & 0.190 & 8.7548 & 0.948 \\
\hline & 111 & $20 \quad 0.007$ & -0.023 & 8.7591 & 0.965 \\
\hline 101 & 1 d 1 & $21-0.109$ & -0.095 & 9.8783 & 0.556 \\
\hline 101 & 141 & $22-0.104$ & -0.100 & 10.931 & 0.848 \\
\hline 11 & 101 & $23-0.021$ & -0.122 & 10.975 & 0.963 \\
\hline 1ㄴ 1 & 101 & $24-0.125$ & -0.107 & 12.577 & 0.844 \\
\hline
\end{tabular}

Table 7. Forecast demand in 2021 of TMBL1

\begin{tabular}{c|c}
\hline Month & Forecast demand \\
\hline January & 1663 \\
Febuary & 1666 \\
March & 1688 \\
April & 1667 \\
May & 1555 \\
June & 1561 \\
July & 1478 \\
August & 1526 \\
September & 1546 \\
October & 1567 \\
November & 1582 \\
December & 1610 \\
Total & 19109
\end{tabular}




\subsubsection{Comparing the forecasting models}

To consider whether ARIMA is the best model for product demand or not, we will compare it with the predictive models via error measurement. In this study, Holt's model and a trend forecasting regression model are processed by Eview to compare the forecast's performance with ARIMA. The error measurements include: Mean absolute deviation [23], Mean Absolute Percent Error (MAPE), Root Mean Squared Error (RMSE). The result of Holt's regression can show in Figure 6. When considering measuring error values (Table 8), we found that the ARIMA model is the best forecasting demand model.

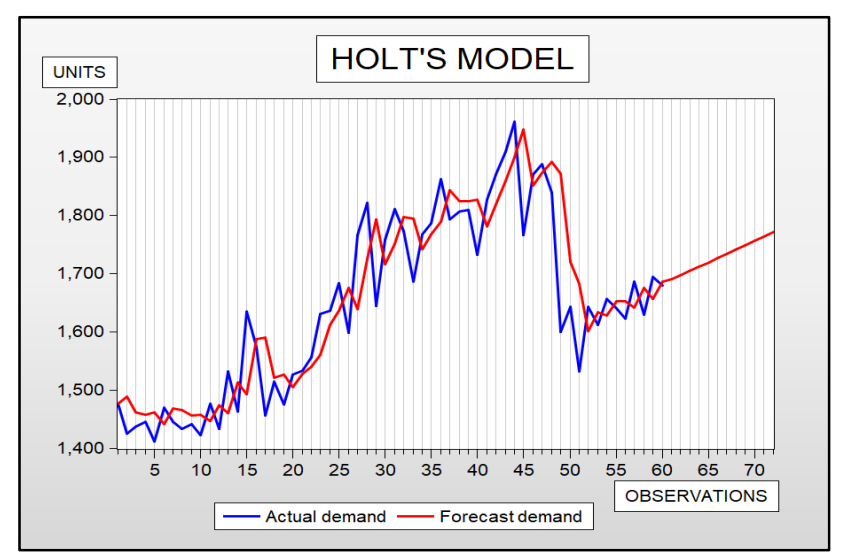

Fig. 6. Holt's regression model of TMBL1.

Table 8. The results of measuring the error of the two models

\begin{tabular}{c|cc}
\hline $\begin{array}{c}\text { Error } \\
\text { measurement }\end{array}$ & Holt's & ARIMA (1,1,16) \\
\hline MAD & 56 & 42 \\
MAPE & $3.40 \%$ & $2.61 \%$ \\
RMSE & 73.71 & 55.61 \\
\hline
\end{tabular}

\subsection{Inventory planning}

After conducting the demand forecast, the study will propose a production policy by developing a "Fuzzy economic production quantity" model. The model parameters are determined as follows: product demand in 2021 results from previously performed forecasts, a production line simulation to determine production speed, storage costs, and expenses of production setup fee will be considered by the fuzzy method. The model results will indicate the optimal batch size for each production batch and determine the number of times to be produced per year.

\subsubsection{Review of the current situation}

Currently, the company is planning a continuous inventory production policy. In this model, researchers will continuously control the inventory. When the goods are left a certain quantity, the company will produce an amount to maintain the maximum inventory level, which has been predetermined. The model's advantage is that the inventory level is closely monitored, helping the manager update inventory continuously. However, the production setup costs are high and make it difficult to plan production. Moreover, irregular customer demand sometimes makes too much inventory or sometimes not enough to meet demand. Therefore, the study builds the "Fuzzy Economic Production Quantity" model to help reduce costs but still meet the demand.

\subsubsection{Determination of parameters}

\subsubsection{Production speed}

The actual survey and recording showed that the production process consists of 66 stages corresponding to 66 workstations and divided into 6 clusters. The simulation model will be built using Arena software following the actual diagram of the production line. Before conducting the simulation, we must analyze each workstation's operation time; these data are sampled and averaged to ensure objectivity. Use the Input Analyzer tool of Arena software to process the input data. The Input Analyzer tool helps analyze and define the time distribution function for each workstation. First, we need to determine the suitable sample size for each workstation's time study in the line. We will have to measure the random ten times at each workstation and use the formula below to determine the most appropriate sample size to collect. The results of the calculation of samples to be collected are shown in Table 9 [34].

Standard deviation: $\mathrm{s}=\sqrt{\frac{\sum_{\mathrm{i}=1}^{\mathrm{i}=\mathrm{n}}\left(\mathrm{x}_{\mathrm{i}}-\overline{\mathrm{x}}\right)^{2}}{\mathrm{~N}-1}}$

Sample size: $\mathrm{n}=\left(\frac{\mathrm{ts}}{\mathrm{k}}\right)^{2}$

Annotate:

$\mathrm{x}_{\mathrm{i}}$ : The time measured in times $\mathrm{i}$

$\overline{\mathrm{x}}$ : average time of all time measurements

$\mathrm{N}$ : random sample size $(\mathrm{N}=10)$

$\mathrm{t}$ : Student distribution (look up the t-distribution table)

$\mathrm{k}$ : acceptable mean error $(\mathrm{k}=0.05)$

Table 9. The sample sizes of each workstation

\begin{tabular}{c|c|c|c|c|c}
\hline Work station & Sample size & Work station & Sample size & Work station & Sample size \\
\hline WS1 & 3 & WS23 & 1 & WS45 & 2 \\
WS2 & 2 & WS24 & 22 & WS46 & 7 \\
WS3 & 4 & WS25 & 4 & WS47 & 2 \\
WS4 & 30 & WS26 & 19 & WS48 & 1 \\
WS5 & 23 & WS27 & 10 & WS49 & 11 \\
WS6 & 5 & WS28 & 25 & WS50 & 5 \\
WS7 & 25 & WS29 & 1 & WS51 & 22 \\
WS8 & 11 & WS30 & 9 & WS52 & 24 \\
WS9 & 17 & WS31 & 1 & WS53 & 21 \\
WS10 & 10 & WS33 & 3 & WS54 & 10 \\
WS11 & 8 & WS34 & 2 & WS55 & 1 \\
WS12 & 12 & & & WS56 & 11
\end{tabular}


Tran Thi Bich Chau Vo, Phan Hung Le, Nhut Tien Nguyen, Thi Le Thuy Nguyen and Ngoc Hien Do/ Journal of Engineering Science and Technology Review 14 (2) (2021) 80 - 89

\begin{tabular}{l|c|c|c|c|c} 
WS13 & 8 & WS35 & 3 & WS57 & 2 \\
WS14 & 1 & WS36 & 11 & WS58 & 1 \\
WS15 & 12 & WS37 & 1 & WS59 & 1 \\
WS16 & 6 & WS38 & 7 & WS60 & 3 \\
WS17 & 14 & WS39 & 23 & WS61 & 1 \\
WS18 & 30 & WS40 & 28 & WS63 & 2 \\
WS19 & 26 & WS41 & 10 & WS64 & 1 \\
WS20 & 2 & WS42 & 29 & WS65 & 11 \\
WS21 & 5 & WS43 & WS44 & WS66 & 21 \\
WS22 & 2 & & &
\end{tabular}

From the sample size table proposed for the stages, select the maximum sample size $\mathrm{n}=30$ to analyze the work station's time distribution function. Table 10 shows the time distribution function of each workstation after 30 times have been timed.

After having the input data, then we will develop a simulation model with the following assumptions: the production process took place continuously, uninterrupted by reasons such as lack of semi-finished products, shut down due to damage, absence of workers; the travel time and compensation activities of the workers have been calculated, and the product quality of the production line is $100 \%$. The simulation model is based on all the inputs illustrated in Figure 7. The model was set to operate for 8.75 hours/day and was repeated ten times. The output shown in Figure 8 shows the production speed of the line of 434 products/day.

\subsubsection{Inventory costs}

In the production system, the production cost is determined to include the following components: labor cost, material cost, and indirect cost. Based on the data, this cost is defined as $\mathrm{P}$ $=45000 \mathrm{VND} /$ product. Trapezoidal fuzzy numbers will consider storage costs $(\mathrm{H})$ and production setup costs $(\mathrm{C})$. The estimation method consists of 3 steps: cost analysis into components, component cost estimation, and synthesis of component costs.

Storage costs include warehouse operating costs, tax and insurance costs, and storage maintenance costs. Production setup costs include raw material transportation costs, planning costs, and line inspection costs. After analyzing the cost into component costs, we estimate these component costs through consultation with the company and modeled by the general trapezoidal fuzzy number of form A (a, b, c, d), where:

- $\mathrm{a}=$ the lower bound expected cost range.

$-\mathrm{b}=$ the upper determined expected cost range.

- $\mathrm{c}=$ the lower bound expected cost range - the smallest cost value.

- $d=$ the upper determined common cost range - the most significant cost value.

After estimating the component costs, we add up the component costs. For a trapezoidal component cost, the estimated total fee is also trapezoidal. Table 11 and Table 12 show the calculated results of the cost of storage and production setup costs. Then, we will consider charges blurred by the set $\alpha$ of defined by the upper and lower bound by the following formula: $\mathrm{L} \alpha=\mathrm{c} \alpha+\mathrm{a}-\mathrm{c}$ and $\mathrm{U} \alpha=\mathrm{b}+\mathrm{d}-$ $\mathrm{d} \alpha(3)$

Table 10. The time distribution function of workstations

\begin{tabular}{|c|c|c|c|}
\hline $\begin{array}{l}\text { Work } \\
\text { station }\end{array}$ & $\begin{array}{c}\text { Time distribution function } \\
\text { (seconds) }\end{array}$ & $\begin{array}{c}\text { Work } \\
\text { station }\end{array}$ & $\begin{array}{c}\text { Time distribution function } \\
\text { (seconds) }\end{array}$ \\
\hline WS1 & $21.3+0.25 * \operatorname{BETA}(1.06,1.03)$ & WS34 & UNIF(27.1, 29.4) \\
\hline WS2 & $\operatorname{TRIA}(27.3,30.8,32.5)$ & WS35 & $20+2 * \operatorname{BETA}(0.91,1.37)$ \\
\hline WS3 & $\operatorname{TRIA}(23,28.5,34)$ & WS36 & $19.3+2.23 * \operatorname{BETA}(1.3,1.54)$ \\
\hline WS4 & $7+\operatorname{WEIB}(0.958,1.44)$ & WS37 & $35+2 * \operatorname{BETA}(0.812,1.11)$ \\
\hline WS5 & $\operatorname{TRIA}(5.61,8.67,9.69)$ & WS38 & $14.2+2.15 * \operatorname{BETA}(1.42,1.67)$ \\
\hline WS6 & $18+5 * \operatorname{BETA}(1.42,1.87)$ & WS39 & $36.3+2.3 * \operatorname{BETA}(1.19,1.52)$ \\
\hline WS7 & $3.07+4.93 * \operatorname{BETA}(2.11,1.6)$ & WS40 & $\operatorname{UNIF}(8.29,10.6)$ \\
\hline WS8 & $10+2 * \operatorname{BETA}(0.863,0.898)$ & WS41 & TRIA $(9.56,11.5,11.9)$ \\
\hline WS9 & $9+4.74 * \operatorname{BETA}(2.29,1.77)$ & WS42 & $13+2.22 * \operatorname{BETA}(0.727,1.05)$ \\
\hline WS10 & TRIA $(11.4,13.7,16)$ & WS43 & $7.7+2.3 * \operatorname{BETA}(1.24,1.37)$ \\
\hline WS11 & $\operatorname{TRIA}(17.2,21.1,21.8)$ & WS44 & $\operatorname{UNIF}(15.5,17.8)$ \\
\hline WS12 & $8+4.73 * \operatorname{BETA}(1.76,2.55)$ & WS45 & $29+2.27 * \operatorname{BETA}(1.38,1.29)$ \\
\hline WS13 & TRIA( $(10.1,13.2,14.6)$ & WS46 & TRIA(11.5, 13.1, 13.8) \\
\hline WS14 & $34.6+2.26 * \operatorname{BETA}(1.14,1.33)$ & WS47 & $33.4+2.3 * \operatorname{BETA}(1.22,1.52)$ \\
\hline WS15 & $8+3 * \operatorname{BETA}(1.06,1.03)$ & WS48 & $40.8+2.06 * \operatorname{BETA}(1.46,1.81)$ \\
\hline WS16 & TRIA( $(15.4,17.7,20)$ & WS49 & $12.4+1.94 * \operatorname{BETA}(1.74,1.43)$ \\
\hline WS17 & $10+2.24 * \operatorname{BETA}(2.11,1.56)$ & WS50 & $20.4+2.3 * \operatorname{BETA}(0.935,0.982)$ \\
\hline WS18 & $4.74+1.99 * \operatorname{BETA}(1.19,1.02)$ & WS51 & $\operatorname{UNIF}(8.46,10.6)$ \\
\hline WS19 & $5+2 * \operatorname{BETA}(1.03,1.07)$ & WS52 & $\operatorname{TRIA}(5.45,7.02,7.69)$ \\
\hline WS20 & $\operatorname{TRIA}(32.5,36,37.5)$ & WS53 & $8.79+2.17 * \operatorname{BETA}(1.05,0.913)$ \\
\hline WS21 & $20.2+2.33 * \operatorname{BETA}(1.24,1.12)$ & WS54 & $\operatorname{TRIA}(16.2,17.9,18.6)$ \\
\hline WS22 & $\operatorname{TRIA}(14,16.8,19.6)$ & WS55 & $26.1+2.28 * \operatorname{BETA}(1.06,1.66)$ \\
\hline WS23 & $\operatorname{TRIA}(33,36.1,37.5)$ & WS56 & $\operatorname{TRIA}(9.08,10.7,11.4)$ \\
\hline WS24 & $\mathrm{UNIF}(6.42,8.82)$ & WS57 & $34.3+2.27 * \operatorname{BETA}(1.31,1.16)$ \\
\hline WS25 & $\operatorname{TRIA}(17.3,20.6,22)$ & WS58 & $50.8+2.22 * \operatorname{BETA}(1.17,1.05)$ \\
\hline WS26 & $5.75+1.96 * \operatorname{BETA}(1.2,1.3)$ & WS59 & $42.5+2.17 * \operatorname{BETA}(1.44,1.76)$ \\
\hline WS27 & $\operatorname{TRIA}(13.2,14.3,15.4)$ & WS60 & $\operatorname{TRIA}(28.3,30.5,31)$ \\
\hline
\end{tabular}


Tran Thi Bich Chau Vo, Phan Hung Le, Nhut Tien Nguyen, Thi Le Thuy Nguyen and Ngoc Hien Do/ Journal of Engineering Science and Technology Review 14 (2) (2021) 80 - 89

\begin{tabular}{l|l|l|l} 
WS28 & $7+2 * \operatorname{BETA}(0.701,0.974)$ & WS61 & $42.7+2.28 * \operatorname{BETA}(1.13,0.936)$ \\
WS29 & TRIA $(48,50.6,52.6)$ & WS62 & TRIA $(35.1,36.9,37.4)$ \\
WS30 & UNIF $(20.1,22.5)$ & WS63 & $100+2.33 *$ BETA $(1.57,1.33)$ \\
WS31 & $42.4+5.12 *$ BETA $(3.06,2.04)$ & WS64 & UNIF $(38.5,40.7)$ \\
WS32 & TRIA $(34.2,36,36.2)$ & WS65 & TRIA $(11.1,11.9,13.5)$ \\
WS33 & TRIA $(37.8,38.8,39.9)$ & WS66 & UNIF $(8.09,10.5)$ \\
\hline
\end{tabular}

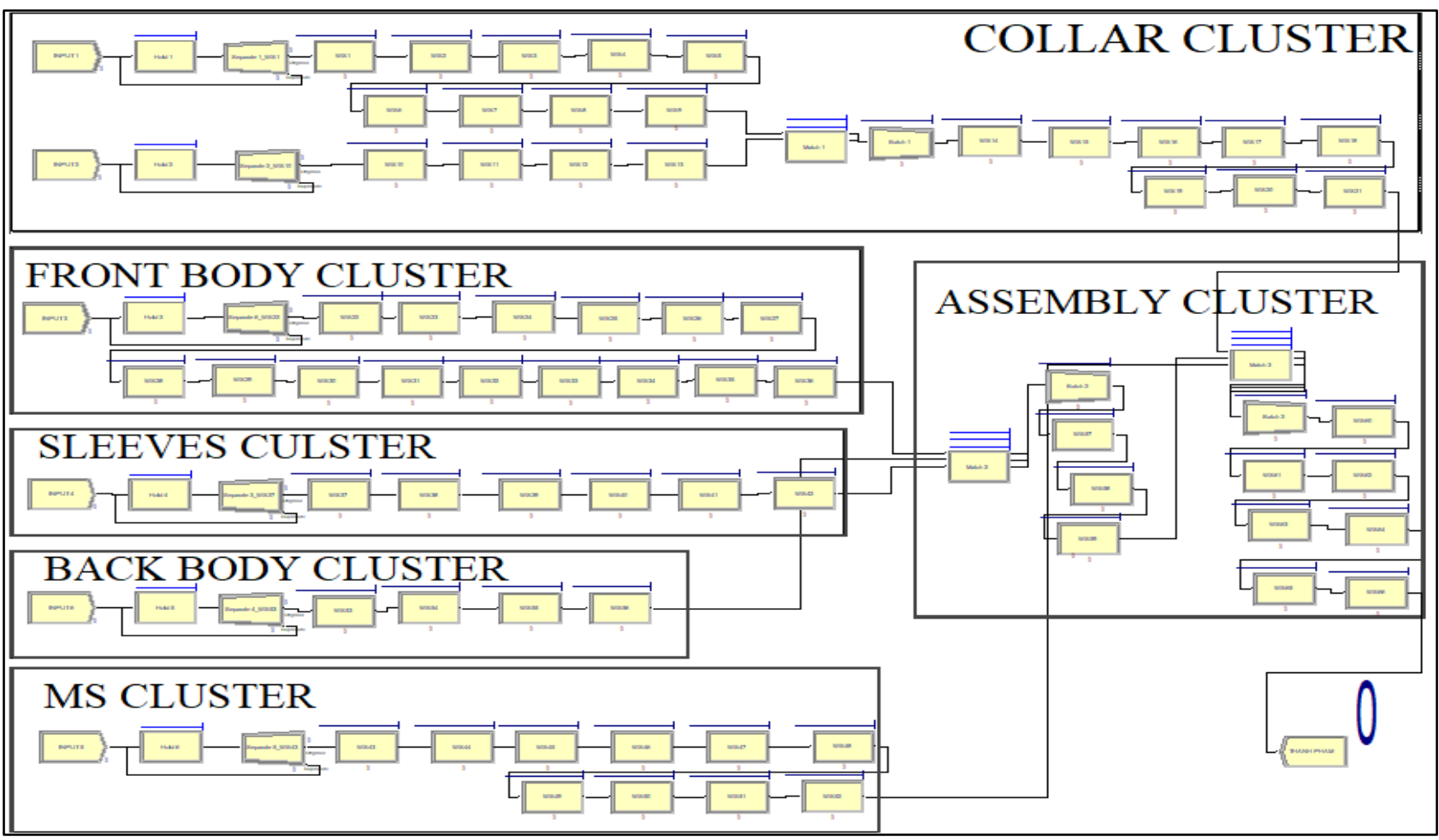

Fig. 7. Simulation model of the long sleeve shirt production line.

\begin{tabular}{|c|c|}
\hline Replications: 10 & Tire Lnits : Hours \\
\hline & Key Performance Indicators \\
\hline $\begin{array}{l}\text { System } \\
\text { Number Out }\end{array}$ & $\begin{array}{l}\text { Average } \\
434\end{array}$ \\
\hline
\end{tabular}

The storage cost is the trapezoidal fuzzy number as follows: $\mathrm{H}=(6600,8000,1700,1500)$. The cutting set $\mathrm{H}_{\alpha}$ is determined by the upper and lower bound as follows: $\mathrm{LH}_{\alpha}=$ $1700_{\alpha}+4900$ (4) and $\mathrm{UH}_{\alpha}=9500-1500_{\alpha}(5)$

Fig. 8. Simulation model outputs

Table 11. Estimating the cost of storage

\begin{tabular}{c|cccc}
$\begin{array}{c}\text { Storage costs } \\
\text { (VND/unit.year) }\end{array}$ & $\begin{array}{c}\text { The smallest cost } \\
\text { value }\end{array}$ & Common cost range & $\begin{array}{c}\text { The biggest cost } \\
\text { value }\end{array}$ \\
\hline Warehouse operating & 2500 & Lower & Upper & 3300 \\
Tax and insurance & 1300 & 1700 & 2500 & 3000 \\
Storage maintenance & 1100 & 1900 & 2200 & 2600 \\
Total & 4900 & 6600 & 8000 & 9500 \\
\hline
\end{tabular}

Table 12. Estimating the cost of production setup

\begin{tabular}{l|c|c|c|c}
\hline Production setup (VND/time) & $\begin{array}{c}\text { The smallest cost } \\
\text { value }\end{array}$ & \multicolumn{2}{c|}{$\begin{array}{c}\text { Common cost range } \\
\text { Lower }\end{array}$} & $\begin{array}{c}\text { The biggest cost } \\
\text { value }\end{array}$ \\
\hline Raw-material transportation & 70000 & 85000 & 95000 & 150000 \\
Planning & 30000 & 45000 & 60000 & 80000 \\
Line inspection & 300000 & 400000 & 600000 & 640000 \\
Total & 400000 & 530000 & 755000 & 870000 \\
\hline
\end{tabular}

The storage cost is the trapezoidal fuzzy number as follows: $\mathrm{C}=(530000,755000,130000,115000)$. The cutting set $\mathrm{C}_{\alpha}$ is determined by the upper and lower bound as follows: $\mathrm{LC}_{\alpha}=130000 \alpha+400000\left({ }^{\wedge}\right)$ and $\mathrm{UC}_{\alpha}=870000-115000 \alpha$ (7).

\subsubsection{Total demand and number of working days in 2021}

Based on the forecast aggregate results in Table 3, we demand that TMBL1 is 19109 products in 2020. On the other hand, the company will have 52 Sundays and 20 holidays. Therefore, the number of working days in $2021: \mathrm{N}=365-(52$ $+20)=293$ (days).

We define the daily demand rate as follows from the total demand and the number of working days in the year. $\mathrm{r}=\frac{19109}{293}=65$ (products per day). 


\subsubsection{Fuzzy Economic Production Quantity}

We have identified all the necessary parameters to build the model, and these parameters are summarized in Table 8 . The production setup and storage costs are estimated, and the trapezoidal fuzzy model shown in Tables 13 and Table 14. Next, we will determine the optimal production batch size through surveying the "Fuzzy Economic Production Quantity" model.

Table 13. The parameters of the "Fuzzy EPQ" model

\begin{tabular}{c|cc}
\hline Parameters & Value & Unit \\
\hline Total demand in 2021 & 19109 & Products \\
Working days in 2021 & 293 & Days \\
Demand per day & 65 & Products per day \\
Production speed & 434 & Products per day \\
Production cost & 45000 & VND per product \\
\hline
\end{tabular}

First, we have to check the feasibility of the model: $\frac{\text { Demand in the year }}{\text { production speed }}=\frac{19109}{434}=44$ days. Condition test shows that the number of days required to produce demand in the year is less than the number of working days in the year $(44<293)$, so this model is feasible. In the following, we will develop the model to participate in two fuzzy numbers of storage costs $(\mathrm{H})$ and production setup costs (C). The model cut set $\alpha$ is determined as shown below (LQ $\alpha^{*}$ and $\mathrm{UQ}^{*}$ are upper bound and lower bound of optimal production batch size by cutting set $\alpha$ ). With 11 cuts of $\alpha$ evenly distributed from 0 to 1 , we determine the cut sets of $Q^{*}$ as in Table 14.

$$
\begin{aligned}
& \mathrm{LQ}_{\alpha}{ }^{*}=\sqrt{\frac{\mathrm{LC}_{\alpha}}{\mathrm{UH}_{\alpha}}} \times \sqrt{\frac{2 \times \mathrm{R} \mathrm{xp}}{\mathrm{p}-\mathrm{r}}}=\sqrt{\frac{130000 \alpha+400000}{9500-1500 \alpha}} \times \sqrt{\frac{2 \times 19109 \times 434}{434-65}}(8) \\
& \mathrm{UQ}_{\alpha}{ }^{*}=\sqrt{\frac{\mathrm{UC}_{\alpha}}{\mathrm{LH}_{\alpha}}} \times \sqrt{\frac{2 \times \mathrm{R} \times \mathrm{p}}{\mathrm{p}-\mathrm{r}}}=\sqrt{\frac{870000-115000 \alpha}{1700_{\alpha}+4900}} \times \sqrt{\frac{2 \times 19109 \times 434}{434-65}}(9)
\end{aligned}
$$

$\underline{\text { Table 14. Cutting sets } \alpha \text { of production lot size Q * }}$

\begin{tabular}{l|c|c|c|c|c|c}
\hline \multicolumn{1}{c|}{$\boldsymbol{\alpha}$} & $\mathbf{L H}$ & $\mathbf{U H}$ & $\mathbf{L C}$ & $\mathbf{U C}$ & $\mathbf{L Q}^{*}$ & $\mathbf{U Q}^{*}$ \\
\hline 0 & 4900 & 9500 & 400000 & 870000 & 1376 & 2826 \\
0.1 & 5070 & 9350 & 413000 & 858500 & 1409 & 2760 \\
0.2 & 5240 & 9200 & 426000 & 847000 & 1443 & 2696 \\
0.3 & 5410 & 9050 & 439000 & 835500 & 1477 & 2636 \\
0.4 & 5580 & 8900 & 452000 & 824000 & 1511 & 2577 \\
0.5 & 5750 & 8750 & 465000 & 812500 & 1546 & 2521 \\
0.6 & 5920 & 8600 & 478000 & 801000 & 1581 & 2467 \\
0.7 & 6090 & 8450 & 491000 & 789500 & 1617 & 2415 \\
0.8 & 6260 & 8300 & 504000 & 778000 & 1653 & 2364 \\
0.9 & 6430 & 8150 & 517000 & 766500 & 1689 & 2316 \\
1 & 6600 & 8000 & 530000 & 755000 & 1726 & 2268 \\
\hline
\end{tabular}

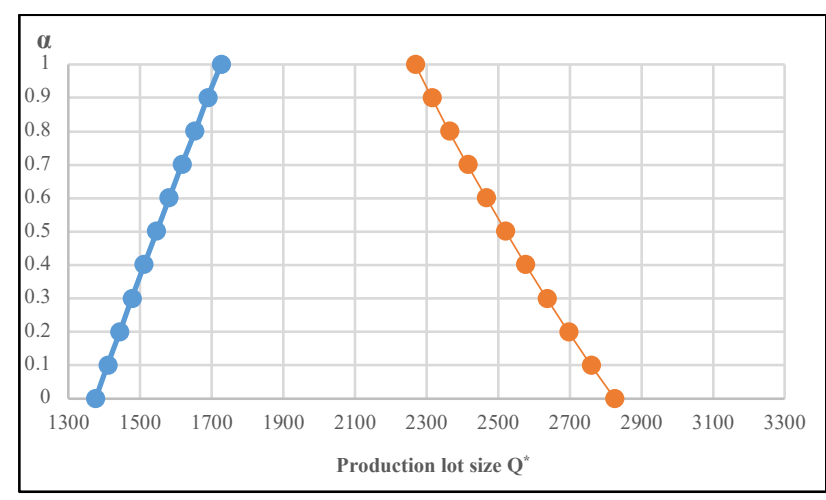

Fig. 9. Ability distribution of production lot size Q

If $\mathrm{Q} *$ is considered a possibility variable, Figure 9 is the variable $\mathrm{Q} *$ ability distribution. Based on this distribution, we can make the most reasonable decisions. In this study, the maximum member function average fuzzy solution was used to determine the optimal production lot size: $\mathrm{Q}^{*}=(1726+$ $2268) / 2=1997$ products. From the surveyed $Q^{*}$ value above, we calculate the number of production times in a year; then, we will determine the actual batch size to meet the correct demand and production time each time. Several production times in a year $\mathrm{m}=19109 / 1997 \approx 10$ (times). We can deduce the actual batch size that must be produced to meet demand $\mathrm{Q}=19109 / 10=1911$ (products) from the number of production times. The time required in each production time $\mathrm{t}=1911 / 434 \approx 4$ (days)

\section{Discussions and conclusions}

The limitations mentioned above have increased costs and reduced its competitiveness, which poses an urgent problem for developing a more effective forecasting and inventory model. This research has proposed solutions to improve enterprise supply capacity by selecting forecasting models and a policy framework for production to ensure optimal inventory. First, the chosen research a forecast model with the lowest error following the data to predict the long-sleeved shirt product named the code TMBL1 with collecting 60 periods from 2016 to 2020. ARIMA $(1,1,16)$ has been selected as the best model to forecast demand in 2021 after comparing Holt's regression model. From data, the EPQ has been built by simulation with Arena software and fuzzy number to determine the best production batch size and suggested the number of times to be produced per year, thereby helping businesses to plan their production significantly. Several production times in a year are ten times, and the actual batch size must produce 1911 quantities, which each production time is four days. From that, this study would like to give some recommendations as well as future research directions as follows 1) Forecasting needs to be continuously monitored and edited, so it is necessary to build follow-up signals to ensure the best forecast; 2) More analysis is required on a company's inventory, including specific inventory costs and production line productivity, to give the most detailed and accurate model parameters; and 3) Therefore, it is recommended to add distribution planning in the future, considering the total transportation distance and considering customer needs and carrying capacity to make the 


\section{Tran Thi Bich Chau Vo, Phan Hung Le, Nhut Tien Nguyen, Thi Le Thuy Nguyen and Ngoc Hien Do/}

\section{Journal of Engineering Science and Technology Review 14 (2) (2021) 80 - 89}

distribution plan more effective. Also, finding the distribution route for the entire distribution system is the next target.

There are still limitations to the research, such as 1) only the TMBL1 product line is researched, while the company still has many other product lines; and 2) the proposed inventory model has not considered the fluctuation of demand and sales plan of the company. The study would like to give future research directions, including research on product distribution to minimize shipping costs, build a flexible inventory management support system, line balance, and other improved activities to enhance its product supply capacity continuously. Due to time constraints, the topic has not studied the process of supplying raw materials and regulating production. Future studies need to continuously research production issues such as inventory planning, line balance, and other improvement activities to improve its product supply capacity continually.

This is an Open Access article distributed under the terms of the Creative Commons Attribution License.

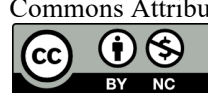

\section{References}

1. M. Werner and K. Heynert, "Open model integration-a review of practical examples in operational flood forecasting," in Proceedings of the Seventh International Conference on Hydroinformatics, 2006, vol. 1 , pp. 155-162.

2. D. Waddell and A. S. Sohal, "Forecasting: The key to managerial decision making," Management Decision, 1994.

3. G. C. Wang, "Forecasting practices in electric and gas utility companies," Practical Guide to Business Forecasting, p. 106, 2005.

4. S.-M. Aghazadeh, "Revenue forecasting models for hotel management," The Journal of Business Forecasting, vol. 26, no. 3, p. 33, 2007.

5. V. L. M. Martins and L. Werner, "Forecast combination in industrial series: A comparison between individual forecasts and its combinations with and without correlated errors," Expert Systems with Applications, vol. 39, no. 13, pp. 11479-11486, 2012.

6. R. R. Andrawis, A. F. Atiya, and H. El-Shishiny, "Combination of long term and short term forecasts, with application to tourism demand forecasting," International Journal of Forecasting, vol. 27, no. 3, pp. 870-886, 2011.

7. P. Newbold, J. K. Zumwalt, and S. Kannan, "Combining forecasts to improve earnings per share prediction: an examination of electric utilities," International Journal of Forecasting, vol. 3, no. 2, pp. 229238, 1987.

8. H. T. Nguyen and N. V. Luong, " Applying ARIMA model to predict comsumerprice index in Vietnam," Journal of Science and Technology, vol. 5, no. 3, 2017.

9. R. J. Hyndman and G. Athanasopoulos, "Forecasting: Principles and Practice Monash University," Australia https://otexts. com/fpp2, 2019.

10. M. E. Nenni, L. Giustiniano, and L. Pirolo, "Demand forecasting in the fashion industry: a review," International Journal of Engineering Business Management, vol. 5, p. 37, 2013.

11. A. Fumi, A. Pepe, L. Scarabotti, and M. M. Schiraldi, "Fourier analysis for demand forecasting in a fashion company," International Journal of Engineering Business Management, vol. 5, no. Godište 2013, pp. 5-30, 2013.

12. J. Mostard, R. Teunter, and R. De Koster, "Forecasting demand for single-period products: A case study in the apparel industry," European Journal of Operational Research, vol. 211, no. 1, pp. 139147, 2011.

13. C. Frank, A. Garg, L. Sztandera, and A. Raheja, "Forecasting women's apparel sales using mathematical modeling," International Journal of Clothing Science and Technology, 2003.

14. M. Shukla and S. Jharkharia, "ARIMA models to forecast demand in fresh supply chains," International Journal of Operational Research, vol. 11, no. 1, pp. 1-18, 2011.

15. P. Udom and N. Phumchusri, "A comparison study between time series model and ARIMA model for sales forecasting of distributor in plastic industry," IOSR Journal of Engineering, vol. 4, no. 2, pp. 32-38, 2014.

16. J. Fattah, L. Ezzine, Z. Aman, H. El Moussami, and A. Lachhab, "Forecasting of demand using ARIMA model," International Journal of Engineering Business Management, vol. 10, p. $1847979018808673,2018$.
17. A. Ang, G. Bekaert, and M. Wei, "Do macro variables, asset markets, or surveys forecast inflation better?," Journal of monetary Economics, vol. 54, no. 4, pp. 1163-1212, 2007.

18. [P. Poncela and E. Senra, "A two factor model to combine US inflation forecasts," Applied Economics, vol. 38, no. 18, pp. 21912197, 2006.

19. C. Garcia-Ascanio and C. Maté, "Electric power demand forecasting using interval time series: A comparison between VAR and iMLP," Energy Policy, vol. 38, no. 2, pp. 715-725, 2010.

20. C. Lack, "Forecasting Swiss inflation using VAR models," Swiss National Bank, 2006.

21. G. Moser, F. Rumler, and J. Scharler, "Forecasting austrian inflation," Economic Modelling, vol. 24, no. 3, pp. 470-480, 2007.

22. Y. Fang, "Forecasting combination and encompassing tests," International Journal of Forecasting, vol. 19, no. 1, pp. 87-94, 2003.

23. S. Bin Syed, N. N. S. Mohamad, N. A. A. Rahman, and R. Suhaimi, "A study on relationship between inventory management and company performance: A case study of textile chain store," Journal of Advanced Management Science, vol. 4, no. 4, 2016.

24. P. Goonatilake, "Inventory control problems in developing countries," International Journal of Operations \& Production Management, 1984.

25. S. W. Chan, R. Tasmin, A. N. Aziati, R. Z. Rasi, F. B. Ismail, and L. P. Yaw, "Factors influencing the effectiveness of inventory management in manufacturing SMEs," in IOP Conference Series: Materials Science and Engineering, 2017, vol. 226, no. 1, p. 012024.

26. R. A. Sarker and L. R. Khan, "An optimal batch size for a production system operating under periodic delivery policy," Computers \& Industrial Engineering, vol. 37, no. 4, pp. 711-730, 1999.

27. W. M. Chan, R. N. Ibrahim, and P. B. Lochert, "A new EPQ model: integrating lower pricing, rework and reject situations," Production Planning \& Control, vol. 14, no. 7, pp. 588-595, 2003.

28. M. Nourelfath, N. Nahas, and M. Ben-Daya, "Integrated preventive maintenance and production decisions for imperfect processes," Reliability engineering \& system safety, vol. 148, pp. 21-31, 2016.

29. C. H. Glock, "Batch sizing with controllable production rates," International Journal of Production Research, vol. 48, no. 20, pp. 5925-5942, 2010.

30. H.-M. Lee and J.-S. Yao, "Economic production quantity for fuzzy demand quantity, and fuzzy production quantity," European Journal of Operational Research, vol. 109, no. 1, pp. 203-211, 1998.

31. S. Islam and T. K. Roy, "A fuzzy EPQ model with flexibility and reliability consideration and demand dependent unit production cost under a space constraint: A fuzzy geometric programming approach," Applied Mathematics and computation, vol. 176, no. 2, pp. 531-544, 2006.

32. G. C. Mahata, "Optimal replenishment decisions in the EPQ model for deteriorating items with fuzzy cost components under retailer partial trade credit financing," International Journal of Operational Research, vol. 12, no. 4, pp. 363-389, 2011.

33. G. E. Box, G. M. Jenkins, G. C. Reinsel, and G. M. Ljung, Time series analysis: forecasting and control. John Wiley \& Sons, 2015.

34. B. W. Niebel and A. Freivalds, Methods, standards, and work design. 2003. 